\title{
Irksome Preseptal Cellulitis Following Squint Surgery- A Case Report
}

\section{Vidhya C*, Prerana Tripathi and Tarika Perikal}

Pediatric Ophthalmology and Strabismus Department, Sankara Eye Hospitals, India *Corresponding Author: Vidhya C, Pediatric Ophthalmology and Strabismus Department, Sankara Eye Hospitals, India.
Received: May 02, 2020

Published: May 18, 2020

(C) All rights are reserved by Vidhya C., et al.

\begin{abstract}
Inflammation of the soft tissues anterior to the orbital septum is termed periorbital cellulitis or pre-septal cellulitis and affects the eyelids and adnexa. Periorbital infections are infrequent but potentially sight threatening complications of strabismus surgery, hence need to be diagnosed and treated at the earliest. Here We report a case of 33 years female who presented with persisting preseptal cellulitis following strabismus surgery due to hypersensitivity reaction to vicryl sutures.
\end{abstract}

Keywords: Irksome Preseptal Cellulitis; Squint Surgery; Inflammation

\section{Introduction}

Inflammation of the soft tissues anterior to the orbital septum is termed periorbital cellulitis or pre-septal cellulitis and affects the eyelids and adnexa [1]. Periorbital infections are infrequent but potentially sight threatening complications of strabismus surgery [2] hence it has to be diagnosed and treated at the earliest. Pre-septal cellulitis due to hypersensitivity reaction to Polyglactin 910 (Vicryl) (Ethicon, Somerville, NJ) suture material has never been reported. It is a commonly used absorbable suture in strabismus surgery. However, it is reported to have low antigenicity and sparse inflammatory infiltrate [3]. Here we report a case of Preseptal cellulitis in post-operative squint surgery which was due to hypersensitivity reaction to suture material.

\section{Case Report}

A 33 years old female patient presented to us with history of squinting since childhood. She gave history of allergic sinusitis and mild asthma. After complete examination, she was diagnosed with Left Superior Oblique palsy with inferior oblique overaction of +3 with exotropia. She underwent squint surgery in left eye under strict aseptic precaution- recession of Lateral rectus and resection of medial rectus with modified Elliot and Nankins procedure for inferior oblique under local anaesthesia. Sutures used were 6-0 vicryl for muscles and 8-0 vicryl for conjunctiva. Surgery was uneventful. Patient was comfortable on post-operative day 1 with minimal congestion and chemosis. Patient was discharged with antibiotic steroid drops to be applied for 4 times in a day for a month.
On $7^{\text {th }}$ Post-operative day (Figure 1), patient presented with sudden onset of irritation and watering in left eye. On examination, patient had lid edema, mucoid discharge with conjunctival congestion. Patient was diagnosed clinically with conjunctivitis. She was started on chloramphenicol/dexamethasone eye ointment 3 times a day, lubricating eye drop, Oral Amoxycillin- Clavulanic acid and oral Diclofenac Sodium. A conjunctival swab was also taken and sent for culture sensitivity, before starting the treatment, which later came out to be negative.

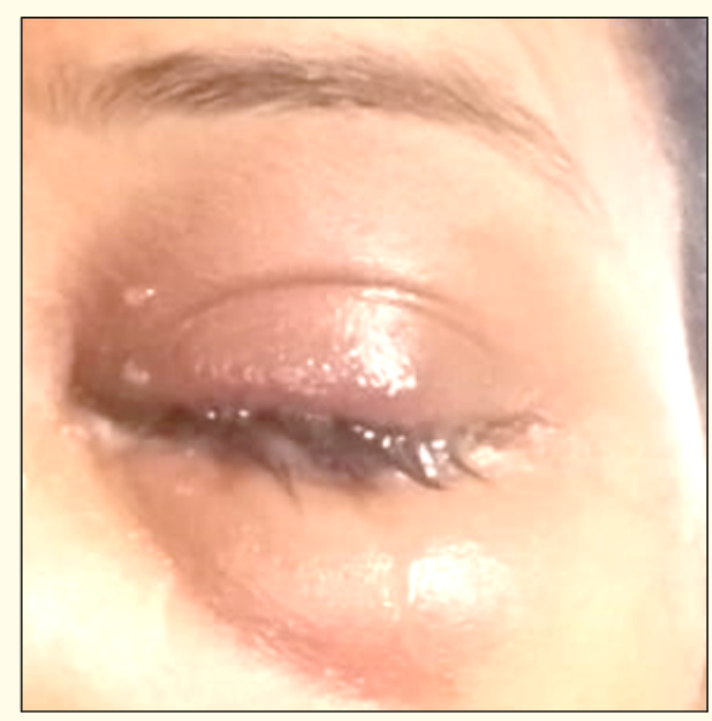

Figure 1: Image showing the lid edema and discharge on postoperative day 7 . 
On post-operative day $11^{\text {th }}$, patient came for follow up with itching in eyes and found to have pre-septal cellulitis with conjunctival congestion. Considering history of sinusitis, a CT scan PNS was taken which showed maxillary sinusitis in the left side. Patient was started on intramuscular injection of cefotaxime $1 \mathrm{~g} /$ day for 7 days and oral Prednisolone acetate $50 \mathrm{mg}$ by the ENT surgeon. However, after 1 week the treatment was stopped with no improvement on preseptal cellulitis, on advice from ENT surgeon asking us to rule out other causes of preseptal cellulitis.

On the $3^{\text {rd }}$ postoperative week (Figure 2), she had persistence of symptoms with severe itching. She had lid edema, full ocular motility, with conjunctival congestion and chemosis along the area of lateral rectus and medial rectus muscle insertion. Conjunctival sutures were removed following which, itching has drastically reduced.

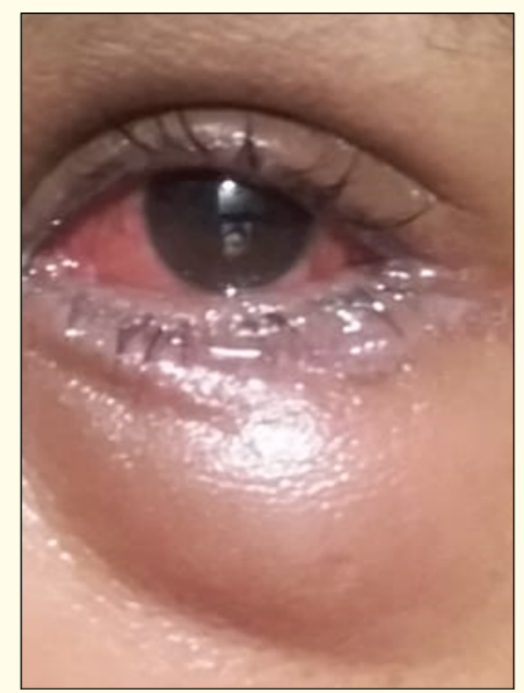

Figure 2: Showing preseptal cellulitis with conjunctival congestion on $3^{\text {rd }}$ postoperative week.

On $4^{\text {th }}$ week (Figure 3), patient presented with preseptal cellulitis along with skin excoriation around the eye. On a suspicion of contact dermatitis due to excessive usage of topical medication, a decision was taken to stop all topical medication and she was started on IV dexamethasone 2cc for 3 days followed by oral Prednisolone $40 \mathrm{mg}$ on slow tapering dose. After this lid edema started to resolve (Figure 4) and patient was comfortable symptomatically. Patient came on $7^{\text {th }}$ week with complete resolution of symptoms.

Throughout the course of condition, patient was taking selfie photographs using her phone everyday and kept sending to us and was regularly following up which helped us to monitor the progression.

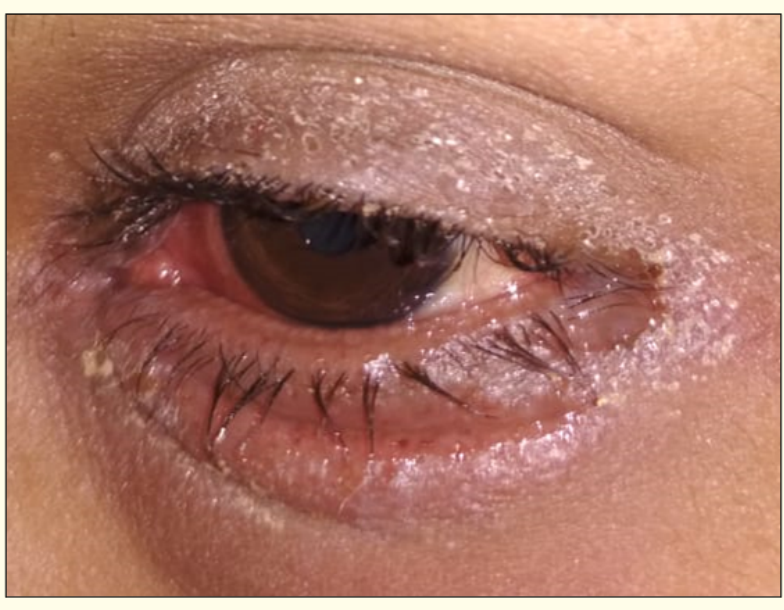

Figure 3: Showing features of contact dermatitis with lid edema on $4^{\text {th }}$ week.

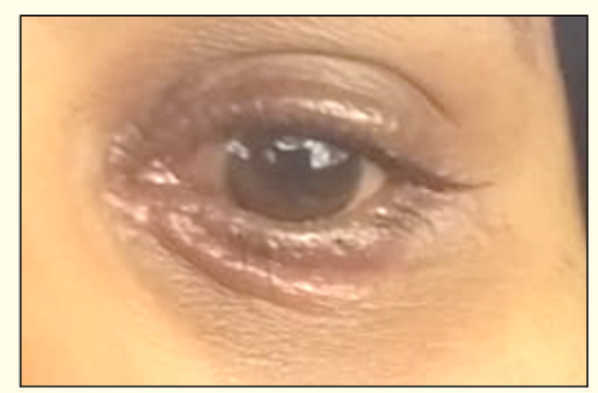

Figure 5: $5^{\text {th }}$ week postoperative picture showing resolving preseptal cellulitis after starting oral steroids.

\section{Discussion}

Periocular infection is very rare following squint surgery. According to various studies, the incidence of periocular infections are in range from 1 in 1100 [4] to 1 in 1900 [5] cases. Source of infection could be intra-operative contamination, self-contamination after surgery due to bad hygiene and not taking proper post-operative measures or due to spread of infection from concomitant sinus infection. In a study conducted by House., et al. [6] Pre-septal cellulitis was found to be in almost $38 \%$ of cases with post-operative infections. Hence suspected an infective cause when the patient first presented with pre-septal cellulitis. But the point that was against the infectious etiology was lack of pain in our patient.

Since the patient had severe itching which typically resolved following removal of sutures, we suspected in terms of hypersensitivity to suture material. The suture used here was polygalctin 910 (vicryl 6-0 for muscle and 8-0 for conjunctiva). Absorption of vicryl 
occurs by hydrolysis, starts by first week and is complete by approximately by 56 - 70 days [7]. Overall incidence to vicryl allergy is $1.5 \%$ [8]. Both immediate and delayed tissue reaction following use of absorbable suture have been described in literature.

The favourable points for the suspected allergic reaction in this case were:

1. History of allergic sinusitis, making the patient more prone for allergies.

2. Symptoms of itching, signs of conjunctival congestion and preseptal cellulitis which started on post-operative day 7 when the possible hydrolysis of suture material would have started.

3. Itching of eye was drastically reduced on removal of conjunctival sutures.

4. Conjunctival hyperemia and swelling over the area of operated muscle.

5. Resolution of pre- septal cellulitis started with systemic steroids.

6. Patient was completely symptoms free by 8 weeks which is approximately the time taken by vicryl sutures to get absorbed.

\section{Conclusion}

To our knowledge, this is perhaps first such reported case. With this case, we want to highlight the fact that Vicryl suture allergy can present with irksome preseptal cellulitis following squint surgery which can confuse the clinician for proper diagnosis and management. Hence, hypersensitivity to suture material must be considered as differential diagnosis for a non-responding preseptal cellulitis following strabismus surgery. We also stress the importance of frequent follow up by patient, continuous communication using technology and documenting recovery through photographs which enables in monitoring progress both for patients and clinician - especially in chronic conditions.

\section{Bibliography}

1. Hauser A and Fogarasi S. "Periorbital and Orbital Cellulitis". Pediatrics in Review 31.6 (2010): 242-249.

2. Wan MJ and Hunter DG. "Complications of Strabismus Surgery: Incidence and Risk Factors". Seminars in Ophthalmology 29.5-6 (2014): 421-428.
3. Far rar M J and Binns MS. "Inflammatory reaction to subcuticular Vicryl suture following tuberculin test". British Journal of Plastic Surgery 50.8 (1997): 665-666.

4. Kivlin JD and Wilson ME. "Periocular infection after strabismus surgery: The Periocular Infection Study Group". Journal of Pediatric Ophthalmology and Strabismus 32.1 (1995): 42-49.

5. Ing MR. "Infection following strabismus surgery". Ophthalmic Surgery 22.1 (1991): 41-43.

6. House RJ., et al. "Postoperative infection following strabismus surgery: case series and increased incidence in a single large referral center". Journal of American Association for Pediatric Ophthalmology and Strabismus 23.1 (2019): 26.e1-26.e7.

7. Helveston EM and Callahan MA. "Synthetic absorbable suture for strabismus surgery". American Journal of Ophthalmology 82.2 (1976): 300-302.

8. Munton CG., et al. "Vicryl (Polyglactin 910): a new synthetic absorbable suture in ophthalmic surgery. A preliminary study". British Journal of Ophthalmology 58.11 (1974): 941-947.

\section{Assets from publication with us}

- Prompt Acknowledgement after receiving the article

- Thorough Double blinded peer review

- Rapid Publication

- Issue of Publication Certificate

- High visibility of your Published work

Website: www.actascientific.com/

Submit Article: www.actascientific.com/submission.php Email us: editor@actascientific.com

Contact us: +919182824667 